\title{
DEVELOPMENT OF A FAN-SHAPED DISTANCE METER SYSTEM FOR MEASURING MOVING ROTOR BLADES - CONCEPT, PHOTOGRAMMETRIC ORIENTATION AND FIRST RESULTS
}

\author{
M. Goering*, T. Luhmann \\ Jade University of Applied Sciences, Institute of Applied Photogrammetry and Geoinformatics (IAPG), \\ Ofener Str. 16/19, 26121 Oldenburg, Germany - (Martina.Goering, Thomas.Luhmann)@jade-hs.de
}

\author{
Commission II, WG II/10
}

KEY WORDS: Fan-shaped distance meter system, laser spot, camera, photogrammetry, sensor fusion, relative orientation, wind turbine, rotor blade torsion

\begin{abstract}
:
For wind turbines, the actual deformation of the rotor blades during operation is of great interest to manufacturers. Photogrammetry and laser scanning are suitable for contactless measurement. The torsion of the rotor blade is of major interest and should be determined with an accuracy of less than $1^{\circ}$. This requires a high precision in the recording distance. The combination of photogrammetry and laser scanning thus enables the acquisition of the relevant data. The nacelle movement is photogrammetrically measured. To measure the torsion, laser scanners in 1D mode are used. A further development of the measuring scenario is a novel fan-shaped distance meter system, presented in this contribution. It consists of four distance measuring units of a Z+F Imager 5006 laser scanner, whose laser beams span a plane in object space. The distance measuring units provide synchronous range measurements. For the calculation of 3D coordinates, their relative orientation is required. Two photogrammetric approaches are presented in this paper. In the first method, the meter system is moved relative to the testfield. The data acquisition and evaluation is complex. In the second method, a stereo camera is built onto the meter system so that $3 \mathrm{D}$ coordinates can be measured directly. This method allows a fast data acquisition and evaluation for system calibration. The realization on a real wind turbine is possible. This contribution discusses challenges and advantages of measuring the rotor blades during operation and presents the realisation of the novel meter system and the determination of the relative orientation. The new meter system makes it possible to measure the torsion during operation of the wind turbines without any targeting with required accuracy.
\end{abstract}

\section{INTRODUCTION}

The deformation of rotor blades during operation of a wind turbine is an interesting topic for turbine manufacturers in order to optimize the rotor blades with regard to aerodynamics, energy yield and material properties. The dimensions and degrees of freedom of wind turbines make them a complex measurement object (Figure 1). The top speed at the outer tip of rotor blades can be up to $80 \mathrm{~m} / \mathrm{s}$ depending on the type of turbine. The rotor blades have a cross section of several meters at the hub, which reduces towards the outer tip. As a result, the rotor blade is less stiff there and severe deformation occurs. The flapping motion at the outer tip is $10 \%$ of the rotor blade length (Edzard, 2009) and a torsion of a few degrees is expected.

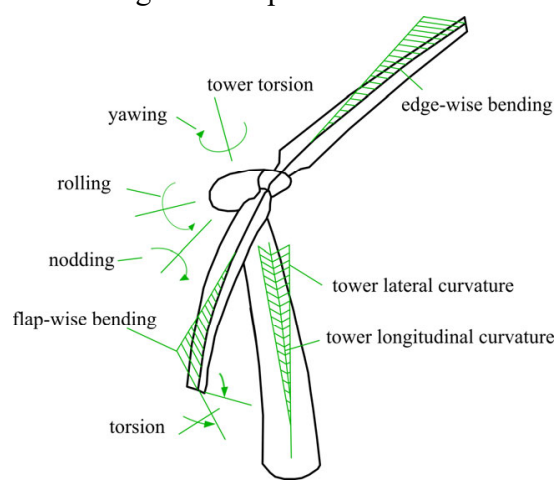

Figure 1. Degrees of freedom (in green) of the wind turbine (adapted from Hau, 2008)
A non-contact and targetless measurement of the deformation must be carried out from the ground in order to provide an approach that is relevant for practical applications. The challenge lies in the required accuracy. Especially the torsion of the rotor blades at the outer tip is relevant for turbine manufacturers and should be determined with an accuracy of less than $1^{\circ}$. The combination of photogrammetric approaches with laser measurement technology offers the potential to achieve the required accuracy. The tower and nacelle movements are recorded photogrammetrically and the deformations - especially the torsion - of the rotor blades are measured with laser technology. Several laser scanners in 1D mode were previously used for this purpose, but their practical application is complicated (Grosse-Schwiep et al., 2013). Therefore, the fanshaped distance meter system (FDMS) is being developed as an optimization and is presented in this paper. It consists of four distance meters that span a plane. This enables the detection of torsion with the required accuracy of less than $1^{\circ}$.

Chapter 2 describes the current state of technology and science. Chapter 3 shows the previous method with several synchronous laser scanners. As an improvement to the laser scanners, a new measuring system consisting of individual distance meters is developed and presented in chapter 4 . Chapter 5 describes the relative orientation of the individual distance meters in the overall system of the FDMS with a static and a dynamic measuring set-up. Finally, a summary and outlook is given in chapter 6.

\footnotetext{
* Corresponding author
} 


\section{RELATED WORK}

To improve plant monitoring during operation, various monitoring techniques are already being installed (García Márquez et al., 2012). Strain gauges can be attached to the rotor blades. However, these are susceptible to errors, especially temperature has a high impact on the results (Papadopoulos et al., 2000). The actual deformation of the blades cannot be adequately described with these strain gauges.

Photogrammetric methods are suitable for optical detection. First measurements on a real turbine with a stereo camera system were published in Corten (1996). The wind turbine was covered with a retro-reflective dot pattern to record vibrations from the tower and the rotor blades.

In Schmidt Paulsen et al. (2009), the tower and rotor blades were covered with retro-reflective targets and observed with two synchronized stereo camera systems. Özbek (2013) demonstrated that the random error of the measurement is in the order of $\pm 5 \mathrm{~mm}$. This value is in line with expectations. Furthermore, a systematic proportion of up to approx. $30 \mathrm{~mm}$ could be detected for marks at the tip of the blade. It is assumed that there is a correlation between the position of the mark in the image and the systematic error.

In another project, the rotor blade is covered with a dot pattern at four positions and observed by two cameras (Winstroth et al., 2014; Winstroth, Seume, 2015). Relative deformation to a reference time can be calculated. The measured points of a rotor blade rotation determine a plane whose axis of rotation is assumed as the coordinate origin.

As an alternative meter system, a laser scanner offers the possibility of contactless acquisition without targets. If the laser scanner or the measuring object is in motion, this is called kinematic terrestrial laser scanning. The movement must be detected by additional sensors for a geometrical correction. A typical application is mobile mapping. Here the laser beam is deflected around an axis and the third dimension is detected by a multi-sensor platform. Wind turbines in operation have been recorded with laser scanners in $1 \mathrm{D}$ and $2 \mathrm{D}$ mode to measure the vibration of the tower (Paffenholz et al., 2008; Gikas, Daskalakis, 2009). In $1 \mathrm{D}$ mode, only the distance measurement is recorded. Thus, during a rotor blade run, the surface of the blade is measured depending on the angle of incidence and the blade shape. The data of the rotor blades have not been analysed further so far. The scanned surface of the blade is called 'profile' in the following. By measuring the profile data at a fixed radius of the blade, differences in the angle of incidence can already be detected. The company Windcomp (2020) uses two distance meters to determine relative deformations of the rotor blades. The distance meter systems aim at the tower at two different distances from the hub.

The usage of the 3D laser scanner mode is presented in Mitka et al. (2019) for a stationary and rotating wind turbine. Simple parameters such as angle difference between rotor blades can be derived from the data.

In Kim et al. (2012) a meter system with three distance meters (1D) is presented which is to support the alignment of ships at mobile ports. The distance meters are arranged in a triangle. The relative orientation is implemented by moving a testfield.

The combination of a targetless photogrammetric approach in combination with laser scanning data is presented in Jepping and
Luhmann (2016). The deformation properties of the wind turbine and rotor blades were derived from the acquired data. With the developed adjustment method, it is possible to derive deformation along the neutral axis of the rotor blade. Their work does not focus the determination of torsion.

\section{METHODOLOGY}

The measurement of profiles of rotor blades offers a lot of potential for the determination of deformation parameters from the ground. To determine the torsion it is necessary to record at least two cross profiles. One is measured directly at the hub to determine the angle of attack. With the other profile on the outer tip the torsion can be derived. Additional profile data provides the possibility to receive further detailed information about the torsion or deformation.

To derive the torsion with an accuracy of less than $1^{\circ}$, a profile with high precision is required. Trigonometrically estimated, a profile accuracy of $15 \mathrm{~mm}$ is required for a blade cross section of $1 \mathrm{~m}$. The shape of a rotor blade hardly changes in relation to the length. It is most noticeable that the rotor blade becomes narrower to the outer tip. Therefore, for a $100 \mathrm{~m}$ rotor blade the position of the profile should be known with an accuracy of $0.5 \mathrm{~m}$ (information from a manufacturer). For a measurement from the ground at a distance of $100 \mathrm{~m}$, this means that the horizontal angle between the meter systems must be known better than $0.25^{\circ}$.

The 3 o'clock position of the rotor blade is used as the relevant measuring position (Figure 2). All distance measuring devices stand on the ground, are aligned at the height of the hub and are distributed over the blade length. Due to the rotation of the blade (rotation angle $\alpha$ ) the distance measuring devices acquire different distances depending on the rotation angle. This enables an angle-based allocation of the measured values.
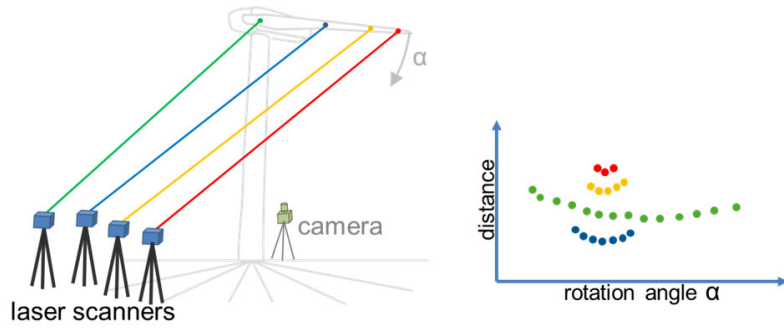

Figure 2. Recording of profile data with distance measuring devices depending on the angle of rotation $\alpha$ from 3 o'clock

Due to the degrees of freedom of the wind turbine, the profile data must be transformed into the coordinate system of the wind turbine or rotor blade (GL, 2012). In addition, the degrees of freedom must be recorded with additional sensor technology (such as a camera). The concept with the use of laser scanners is presented in Grosse-Schwiep et al. (2013). Alternatively, the method of Jepping and Luhmann (2016) can be used to determine the nacelle movements.

The Imager 5010 laser scanner from Zoller + Fröhlich GmbH is used in 1D mode for profile measurement. Since the beam is directed in a fixed direction, this mode is classified in laser class $3 \mathrm{~B}$, and it is dangerous (DIN, 2008). A laser safety officer has to be present in order to avoid hazards. In the test, the actual passing time of the blade through the laser beam was $0.75 \mathrm{sec}$ at the hub and $0.01 \mathrm{sec}$ at the outer tip. Figure 3 shows the measured data for a profile run-through at the outer tip of the rotor blade. At the minimum adjustable measuring frequency of $32 \mathrm{kHz} 300$ 
measured values are recorded at the outer tip. If a polynomial is fitted by the measured values, a standard deviation of less than $2 \mathrm{~mm}$ is resulting (Grosse-Schwiep et al., 2013). This provides a precision for the distance measurement that allows a torsion determination with an accuracy of less than $1^{\circ}$.

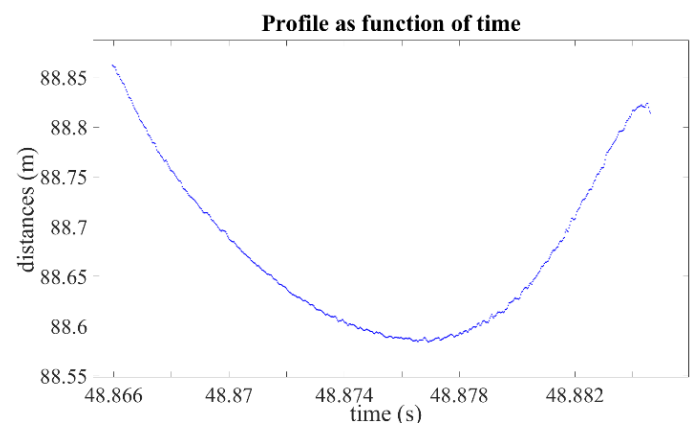

Figure 3. Measured data of a rotor blade run-through at the outer tip with the Z+F Imager 5010 in 1D mode

Using additional sensor equipment, an existing CAD model of the nacelle and various transformations, measured profiles in the coordinate system of the rotor blade can be obtained as a result. For the deformation estimation the CAD model of the rotor blade must be available (Figure 4). This usually can be obtained from the manufacturer or can be determined by procedures given by Jepping and Luhmann (2016). The torsion is derived by adapting the profile data to the CAD model. The large number of measured values simplifies the adaptation to a structureless object like the rotor blade. The determination of the first measured value on the blade is limited by the laser spot size (here $4 \mathrm{~cm}$ at $100 \mathrm{~m}$ ).

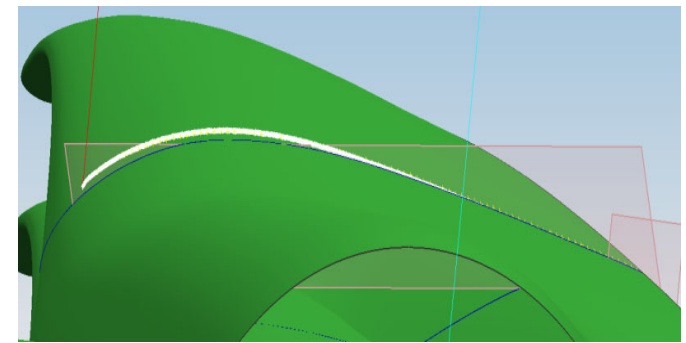

Figure 4. Fitting of profile data (in white) to CAD model (in green)

For the calculation of deformation, the profiles must be measured at the same angle of rotation respectively at the same time. In addition to exact temporal synchronization, perfect spatial alignment and orientation of the distance meters are required. An approach is presented to allow for the estimation of the systems orientation within a lab calibration.

\section{DEVELOPMENT OF THE FAN-SHAPED DISTANCE METER SYSTEM}

The optimization of the approach with laser scanners in 1D mode consists in the development of a new meter system that we call "Fan-shaped distance meter system" (FDMS). The FDMS simplifies the determination of the laser beam alignment on the rotor blades, improves the accuracy of the orientation and represents a cost-effective alternative.

\subsection{Concept}

With the FDMS, several distance meters (at least two) are mounted on a platform (Figure 5). The laser beams are adjusted to span a plane. This also simplifies alignment on a wind turbine with the measurements of the angle of rotation in comparison to multiple alignments of multiple laser scanners (Figure 2).

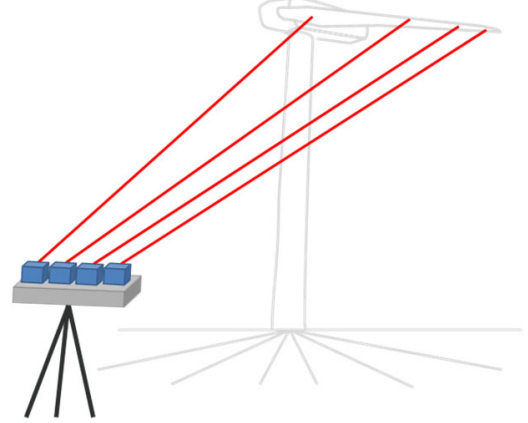

Figure 5. Conceptual design of the fan-shaped distance meter system on a wind turbine

The meter system is mounted on a platform which is equipped with a tilting device. A rotation around the vertical axis is possible for each distance meter. Thus, depending on the measuring arrangement in the laboratory or field test, the horizontal angles can individually be adjusted to the measuring object. The vertical angles of the distance meters are fixed. In addition to the simplified alignment to the rotor blades, another advantage of the meter system is that there are fewer degrees of freedom and presumably fewer error influences.

\subsection{Practical realisation}

The practical realisation of the meter system was carried out by the company Zoller \& Fröhlich GmbH. Four distance meters from the Z+F Imager 5006 series are used for the FDMS (Figure $6)$. The distance meters have an unambiguous range of $87 \mathrm{~m}$ whereby up to three intervals can be measured. Measuring rates between $32 \mathrm{khz}$ and $1 \mathrm{Mhz}$ are possible. The distances are determined using the phase comparison method and are specified with a distance measurement accuracy of $<1 \mathrm{~mm}$, which depends on factors such as the object surface, the angle of incidence and other factors (Eric et al., 2017). The wave length of the measuring laser is at $785 \mathrm{~nm}$, hence in the infrared range. Further sensor characteristics can be taken from $\mathrm{Z}+\mathrm{F}$ (2020). The dimensions of the FDMS are $86 \mathrm{~cm} \times 36 \mathrm{~cm} \times 36 \mathrm{~cm}$ with a weight of approx. $35 \mathrm{~kg}$.

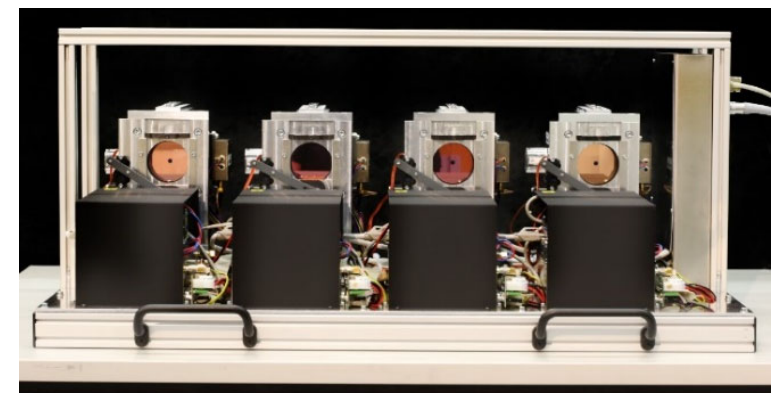

Figure 6. Practical set-up of the fan-shaped distance meter system with four distance meters on a platform

A laser scanner usually measures a reference distance at each zero crossing and applies a correction for the respective rotation. However, this is not possible with distance meters. For this reason, a retractable shutter is installed in each case, for which a calibrated distance is available (Figure 7 left). The shutter can be inserted into the laser beam at definable time intervals and thus 
the effect of a warming up (distance change) of the laser unit can be corrected. Figure 7 on the right shows a telescopic sight that can be attached to the distance meters for easier alignment to the measurement object.

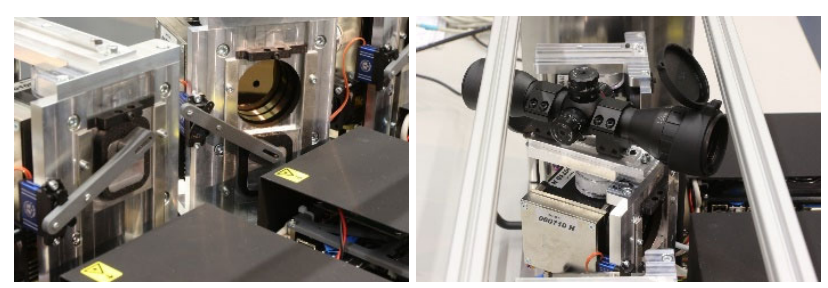

Figure 7. left: two distance meters with one closed and one opened retractable shutter for the reference distance data; right: telescopic sight for alignment to the measurement object

To align the laser beams in a plane, they must represent a line when intersecting with a plane in object space. An adjustment of the laser beams is done by two different recording distances to detect a possible vertical axis error.

The meter system is operated via a laptop with control software. Since the underlying hardware is an off-the-shelf scanner, the control software is fully integrated with the system and all standard commands can be sent to the system via this software, as with any other laser scanner. The distance meters are synchronized internally and can also be synchronized with other sensors, such as a laser scanner or a camera system. For each measured distance, a distance value, a highly linear intensity value and a time stamp are taken via the manufacturer's SDK (Software Development Kit).

\subsection{Combination with camera system}

The transformation into a superior coordinate system is possible by combining the FDMS with a camera. For a test of the meter system, reference data are recorded photogrammetrically under laboratory conditions. For this purpose two high-speed cameras pco.dimax CS3 (PCO, 2020) are attached to the frame of the fan sensor (Figure 8 ). The baseline between them is approximately $1 \mathrm{~m}$.

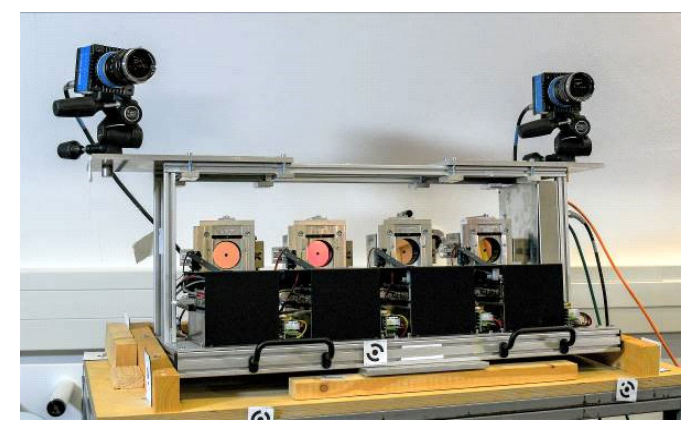

Figure 8. High-speed cameras mounted on fan-shaped distance meter system

\section{RELATIVE ORIENTATION OF THE FAN-SHAPED DISTANCE METER SYSTEM}

Each sensor only detects distances without having a common reference to each other. To calculate $3 \mathrm{D}$ coordinates, the relative orientation of the distance meters must be determined among each other. For each distance meter five unknowns must be estimated, these are the respective positions $(\mathrm{X}, \mathrm{Y}, \mathrm{Z})$ as well as a horizontal and vertical angle $(\gamma, \beta)$ (Figure 9). The coordinate system is located in the right distance meter but it can be transformed to every other of the distance meters or cameras if needed.

After physical adjustment, the laser beams span a plane in object space. A possible deviation from the plane can be checked with the relative orientation and should therefore not be included as a constraint to the adjustment. Thus the orientation between skewed straight lines is determined.

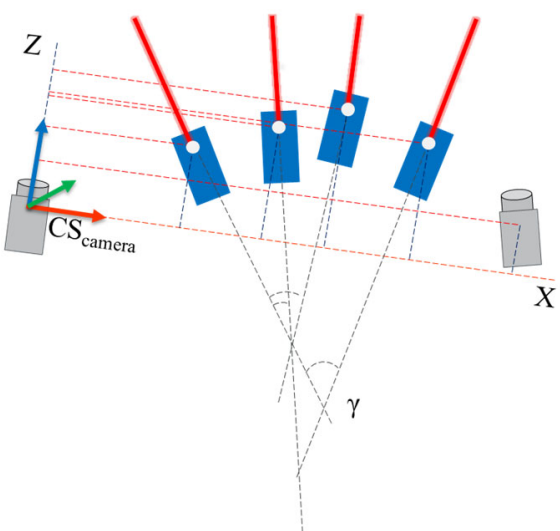

Figure 9. Relative orientation of the fan-shaped distance meter system, coordinate system in a camera ( $\left.\mathrm{CS}_{\text {camera }}\right)$, top view

In the FDMS, each distance meter is mounted on a rotary table so that the horizontal angle $(\gamma)$ can be adjusted according to the application. After each new alignment, the relative orientation must be determined again. If the origin of a distance meter with respect to the rotary table is known, a direct derivation of the relative orientation is possible.

\subsection{Basic workflow}

To determine the relative orientation of the distance measuring devices, it is necessary to move the meter system or a measuring object (Figure 10). Each distance measuring device measures one distance. With a further distance provided by a known movement (shift/rotation - 6DOF) the spatial direction and also the origin of the laser beam can be determined. By two or more measurements, the $3 \mathrm{D}$ coordinates of the laser spot $\left(l_{1-n}\right)$ can be used to define the spatial direction $\vec{p}$ of each laser beam. In order to estimate the 6DOF movement, a photogrammetric approach is chosen which allows for the determination of 3D coordinates of the laser spots $\left(l_{1}, l_{2}\right)$ on a testfield. The coordinate system for this must be on the meter system $\left(\mathrm{CS}_{\text {platform }}\right.$ or $\left.\mathrm{CS}_{\text {camera }}\right)$. The origin $(\mathrm{X}, \mathrm{Y}, \mathrm{Z})$ can be determined with the vector $\overrightarrow{\mathrm{p}}$ and the measured distances (s1n).

Large distance differences $\left(\mathrm{s}_{1}, \mathrm{~s}_{2}\right)$ mean that the calculated spatial direction $\overrightarrow{\mathrm{p}}$ has to be extrapolated to a lower extent and there is less leverage. It is also advantageous if the spatial direction is determined by more than two 3D coordinates $\left(l_{1-n}\right)$. A regression line can be calculated through all 3D coordinates. Together with the measured distances the origin can be determined by an adjustment.

Subsequently, the relative orientation is calculated using the calculated sensor positions $(\mathrm{X}, \mathrm{Y}, \mathrm{Z})$ and the 3D coordinates of the laser spots. For this purpose, the direction vector is determined from which the horizontal $(\gamma)$ and vertical $(\beta)$ angles for each sensor can be derived. 


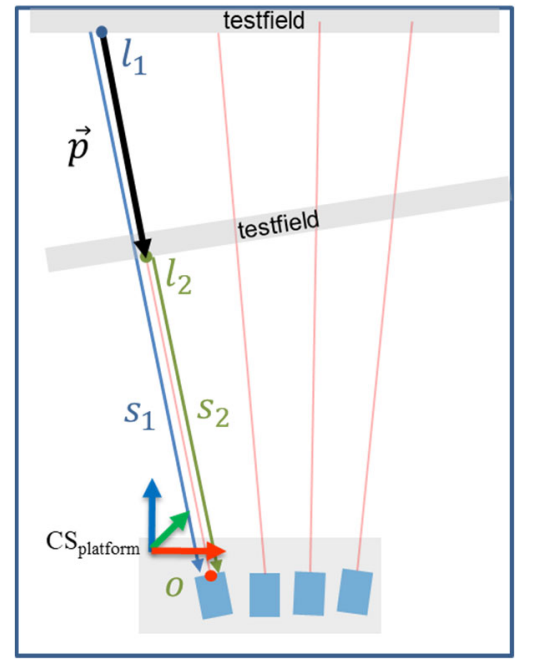

Figure 10. Concept for relative orientation with moving testfield; coordinate system on the platform of meter system (CS $\mathrm{Clatform}_{\text {); }} \overrightarrow{\mathrm{p}}$ direction vector; $\mathrm{s}_{1}$ and $\mathrm{s}_{2}$ measured distances

\subsection{Laser spot measurement}

The laser beam intersects with the measured object and a laser spot can be detected using a camera. The centre of the laser spot is determined photogrammetrically (ellipse star operator Luhmann et al., 2020). The laser spot has a calculated diameter of $3.5 \mathrm{~mm}$ at the laboratory testfield distance and a Gaussian intensity distribution.

The shape of the laser spot in particular depends on the angle of incidence on the target (plane), so that the spot forms an ellipse (Figure 11).
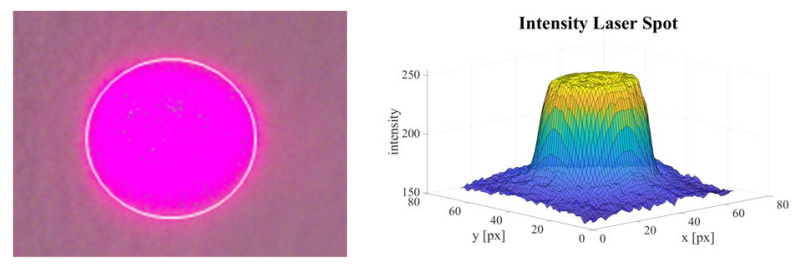

Figure 11. Close-up laser spot with Mamiya ZD camera; left: RGB image with ellipse in white, right: 3D display of the intensities of the red colour channel

Interferences lead to the speckle effect on the laser projection, resulting in an inhomogeneous intensity distribution. Basics for photogrammetric measurement of laser spots with speckle are presented in Clarke, Katsimbris (1994). The speckle effect is dependent on its direction. If the laser spot is photographed with a camera from different positions, the shape results differently. Figure 12 shows the same laser spot recorded at different times and from different spatial directions. Figure 13 shows the intensities of a laser spot acquired with a Mamiya ZD camera. In the red channel, in contrast to the green channel, a high amount of speckle and a blurred ellipse contour can be identified. According to Beraldin (2004), the influence of the speckle on the position can be estimated and would result within $2-5 \mu \mathrm{m}(0.05$ Pixel) for the Mamiya ZD camera setup. However, investigations show that the ellipse centre on this camera varies by 0.3 pixels on average using template matching, which corresponds to $0.03 \mathrm{~mm}$ standard deviation in object space with a maximum deviation of one pixel $(0.1 \mathrm{~mm})$.
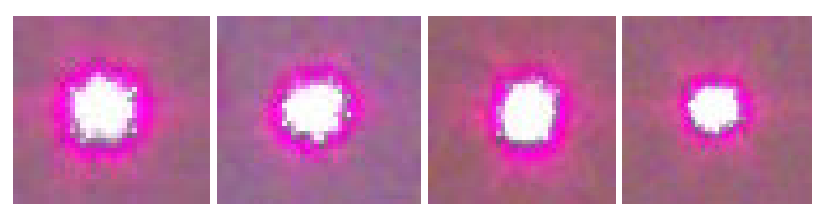

Figure 12. Laser spots from different directions with Mamiya ZD with strong overexposure (white)
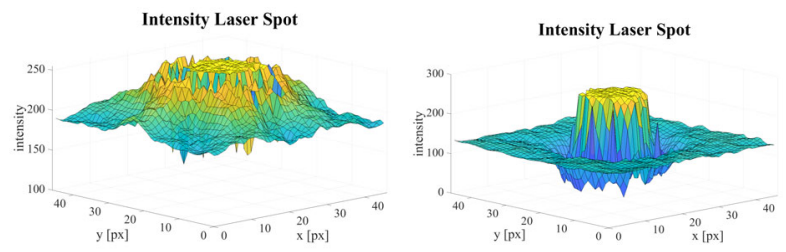

Figure 13. Intensities of a laser spot of the Mamiya ZD; left: red colour channel, right: green colour channel

With the camera Mamiya ZD an image bundle of a fixed test field with the laser spots can be recorded. The overexposure of the laser spots is deliberately used for ellipse measurement, as these can be evaluated with the software AICON 3D Studio. The overexposed area covers 12 pixels in diameter $(0.5 \mathrm{~mm}$ in object space). The bundle adjustment results in an RMS in all coordinate directions of the laser spots of less than $0.1 \mathrm{~mm}$. This camera can be just used for a static setup because a synchronization with other devices is not possible.

For kinematic applications in dynamic setups an RGB camera without infrared filter (CS3 cameras from PCO AG) is used. The camera can be synchronized with the FDMS by sending a TTL trigger signal. Figure 14 shows a laser spot, recorded with this camera at a distance of $3 \mathrm{~m}$. Figure 15 shows intensities of the laser spot of Figure 14. The RGB image and the intensities in the red, green and blue channels are shown. Since the laser has a wavelength of $785 \mathrm{~nm}$ it should be expected that the laser spot would be best visible in the red channel which is confirmed by Figure 14. This channel is used for ellipse measurement in AICON 3D Studio.
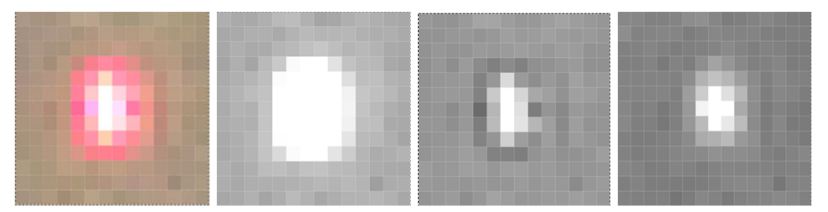

Figure 14. Laser spot on image of the PCO camera; from left to right: RGB image, red, green and blue colour channel

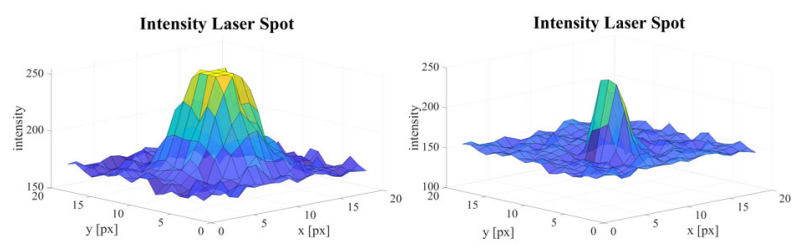

Figure 15. Intensities of a laser spot of the PCO camera; left: red colour channel, right: green colour channel

The available data show that there is much potential for further investigations. The use of a polarization filter can also be tested. 


\subsection{Determining the relative orientation: Method 1}

With this method the relative orientation of the FDMS can be determined by moving the meter system (Figure 16). In this case, a high speed camera does not have to be permanently installed on the system but is used for the transformation into a superior coordinate system in later applications. With this method it is possible to achieve large distances between the $3 \mathrm{D}$ coordinates of the laser spots of the distance meters and thus reduce the above mentioned, unwanted leverage effects of extrapolation.

The alignment of the distance meters is given for a laboratory setup with a model of a wind turbine. The laboratory environment allows a maximum acquisition distance of $10 \mathrm{~m}$. This results in a width of $2 \mathrm{~m}$ for the configuration of the testfield. The principle measurement setup is shown in Figure 17 with part of the test field. The testfield is fixed on a wall due to its required size and the meter system is moved to obtain at least two $3 \mathrm{D}$ coordinates of a laser spot. The coordinate system of the testfield ( $\left.\mathrm{CS}_{\text {testfield }}\right)$ and the platform (CSplatform) is located in the interchangeable target mounts for 1.5" hemispherical targets (Spherically Mounted Reflector or photogrammetric target) on the testfield and on the FDMS. The measurement setup is described in Goering and Luhmann (2017).

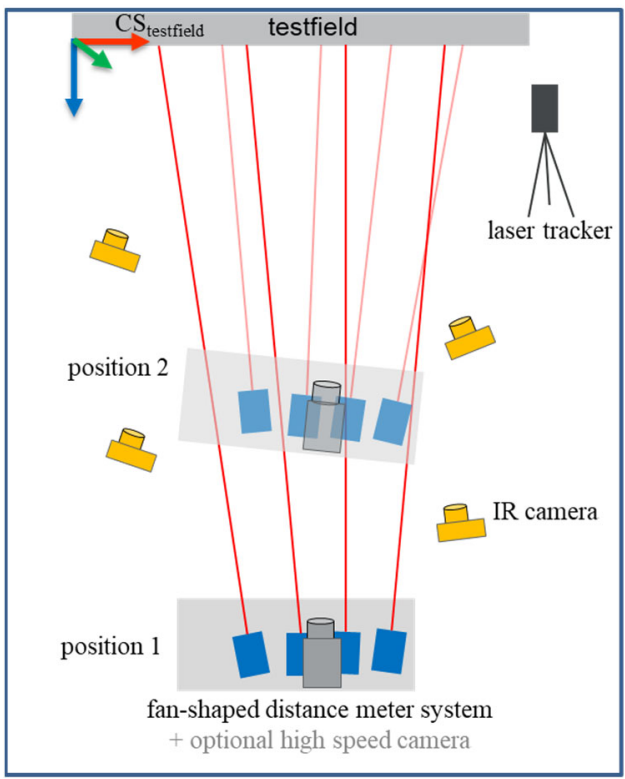

Figure 16. Concept of method 1 for determining the relative orientation

To measure the laser spots in the testfield, an image bundle is taken with the IR camera (Mamiya ZD, yellow camera in Figure 16 , step 1). The accuracy of the image measurements in the bundle was checked and only a minor influence on the relative orientation of the FDMS was found. For practical reasons the testfield is additionally measured with superior quality using a Nikon D2 (step 2). The data sets of Mamiya (each position) are transformed to the data set of the Nikon camera (reference; step 3 ). The result of this step are 3D coordinates of the laser spots of all distance meters in the coordinate system of the testfield (CStestfield).

In order to detect the movement of the meter system, an API T3 laser tracker is applied which uses an interferometer. The laser tracker is used to measure Spherically Mounted Reflector in target mounts on the testfield and on the FDMS (step 4). All data can be transformed into the coordinate system at the meter system

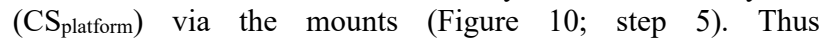

mathematically, the testfield has moved and the spatial direction of the laser beam can be determined from the 3D coordinates of the laser spots (step 6). Applied to the distance of the FDMS, the origin and also the relative orientation can be calculated (step 7).

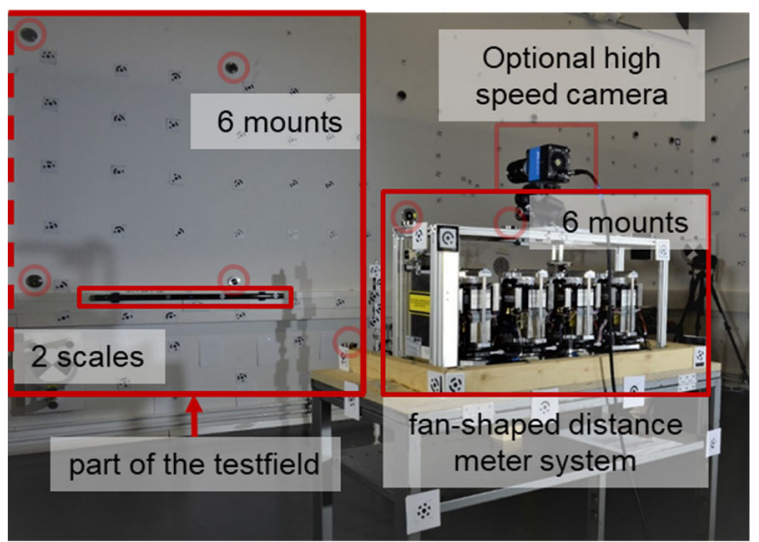

Figure 17. Measurement setup for method 1

Consequently, coordinates of all targets are given in the coordinate system of the meter system ( $\left.\mathrm{CS}_{\text {platform}}\right)$. If a camera is fixed to the meter system (grey camera in Figure 16), the relative orientation can be calculated with known interior orientation using space resection in CSFDMS (step 8). Thus a transformation into a superior coordinate system is provided.

Four positions of the FDMS are recorded in this method. A common solution via a regression line is possible, but also the combination of two positions. The following tables show the result and the respective standard deviations from the combination of two positions. The measurements correlate with each other, but they allow an impression of the measurement procedure.

\begin{tabular}{|l|c|c|c|c|c|}
\hline & \multicolumn{5}{|c|}{ Relative orientation } \\
\hline & $\mathrm{X}[\mathrm{mm}]$ & $\mathrm{Y}[\mathrm{mm}]$ & $\mathrm{Z}[\mathrm{mm}]$ & $\beta\left[^{\circ}\right]$ & $\gamma\left[^{\circ}\right]$ \\
Sensor 1 & 524.6 & 0.0 & 0.0 & 90.0 & 85.4 \\
Sensor 2 & 350.5 & -0.7 & 2.8 & 90.0 & 87.6 \\
Sensor 3 & 175.3 & -0.5 & 1.2 & 90.0 & 89.2 \\
Sensor 4 & 0.0 & 0.0 & 0.0 & 90.0 & 93.7 \\
\hline
\end{tabular}

Table 1. Relative orientation of the fan-shaped distance meter system of method 1 (mean value of six combinations)

\begin{tabular}{|l|c|c|c|c|c|}
\hline & \multicolumn{5}{|c|}{ Standard deviations } \\
\hline & $\mathrm{X}[\mathrm{mm}]$ & $\mathrm{Y}[\mathrm{mm}]$ & $\mathrm{Z}[\mathrm{mm}]$ & $\beta\left[^{\circ}\right]$ & $\gamma\left[^{\circ}\right]$ \\
Sensor 1 & 0.92 & 0.00 & 0.00 & 0.04 & 0.04 \\
Sensor 2 & 1.16 & 1.31 & 2.65 & 0.02 & 0.04 \\
Sensor 3 & 0.49 & 0.93 & 3.73 & 0.02 & 0.05 \\
Sensor 4 & 0.00 & 0.00 & 0.00 & 0.00 & 0.05 \\
\hline
\end{tabular}

Table 2. Standard deviations for relative orientation

The influence of the standard deviations can be calculated using trigonometric techniques. Table 3 shows the influence (linear) for measured values at $100 \mathrm{~m}$ acquisition distance. If the meter system is installed parallel to the rotor blade, the deviation in $\mathrm{X}$ direction describes the uncertainty in position of the profile on the rotor blade. This is less than $0.1 \mathrm{~m}$ and thus below the required position determination of $0.5 \mathrm{~m}$. The simultaneous passage (Figure 2) of a blade is also possible, since the effects are also far below the blade diameter (Y-axis). The Z-component has an effect on the bending of the blade but it is minimal. 


\begin{tabular}{|l|c|c|c|}
\hline & \multicolumn{3}{|c|}{ Impact of standard deviations at 100m distance } \\
\hline & $\mathrm{X}[\mathrm{mm}]$ & $\mathrm{Y}[\mathrm{mm}]$ & $\mathrm{Z}[\mathrm{mm}]$ \\
Sensor 1 & 74.9 & 62.2 & 5.9 \\
Sensor 2 & 74.7 & 44.4 & 5.8 \\
Sensor 3 & 86.5 & 38.4 & 4.8 \\
Sensor 4 & 83.6 & 0.0 & 5.4 \\
\hline
\end{tabular}

Table 3. Impact of standard deviations from relative orientation on $3 \mathrm{D}$ coordinates at $100 \mathrm{~m}$

The effort of measurement and evaluation is very high. Therefore, further independent measurements with this method are not planned.

\subsection{Determining the relative orientation: method 2}

As described in chapter 5.1, the testfield can also be moved instead of the meter system to estimate the relative orientation. For this purpose, a stereo camera system consisting of two CS3 cameras from PCO AG is attached to the FDMS. A typical photogrammetric set of images with synchronous reading of the distances of the FDMS is recorded with respect to the white testfield (step 1). The concept is shown in Figure 18. If the relative orientation of the stereo system is fixed (step 2), 3D coordinates of the laser spots can be determined directly via a pair of images by means of forward intersection (step 3). The subsequent determination of the relative orientation follows the description above (step 4).

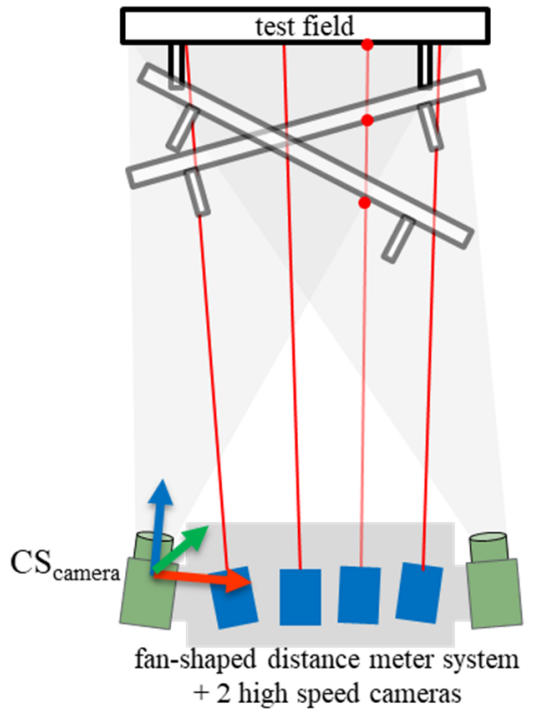

Figure 18. Concept of Method 2 for determining the relative orientation.

This method allows for many positions of the testfield with little effort and thus several 3D coordinates of the laser spots can be determined by forward intersection. The accuracy of the $3 \mathrm{D}$ coordinates is lower than in the described bundle approach with method 1 . However, due to a larger number of $3 \mathrm{D}$ coordinates for each laser spot with the associated distances, the relative orientation can be determined with a similarly high accuracy, compared to method 1. Furthermore, the accuracy can be increased by using an additional camera. The data acquisition and evaluation can be carried out much faster with this method. The disadvantage is, however, that the laser spot measurement at long distances is limited by the used cameras.

Measurements with this method were carried out but not yet evaluated conclusively.

\section{SUMMARY \& OUTLOOK}

For the measurement of rotor blades of wind turbines during operation, a method is presented that combines photogrammetry and laser scanning. As a further development, a new meter system - the fan-shaped distance meter system - is presented. This meter system consists of distance measuring devices that span a plane in object space. During operation of the wind turbine, the rotor blade runs through the laser beams so that the bending (especially the torsion) can be measured. For the determination of $3 \mathrm{D}$ coordinates of the rotor blade, all systems must be given in a common coordinate system. To determine the relative orientation of the developed meter system components, two photogrammetric calibration methods are presented. In both methods, the laser spots of the distance measuring devices must be measured. In the first method the meter system is moved relative to the testfield. Data acquisition and evaluation are complex because different systems are used, e.g. for measuring the position of the FDMS. In the second method, a stereo camera is attached to the meter system. With this system a set of images of a testfield with coded target markers is acquired (testfield is moved) and the $3 \mathrm{D}$ coordinates of the laser spots are determined by forward intersection.

With the known relative orientation, moving objects are recorded in the next step. Measurements are performed on a pipe with a known nominal diameter. Another measurement object is a model of a wind turbine (Figure 19). First experiments for this have been published in Brandt et al. (2017). Reference data should be recorded photogrammetrically. The cameras on the meter system will be used for this purpose.

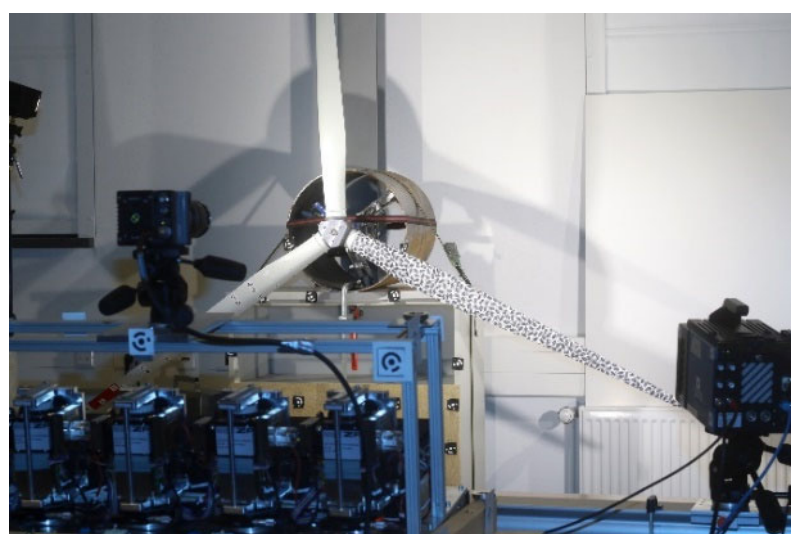

Figure 19. Exemplary test setup for measuring moving rotor blades in the lab.

The deformations of the rotor blades can be measured during operation of the wind turbines. The synchronous acquisition of wind velocities by means of Wind-LiDAR methods (Schneemann et al., 2020) enables the manufacturers of wind energy plants to determine relevant characteristic values for the improvement and monitoring of the plants.

\section{REFERENCES}

Beraldin, J.-A., 2004: Integration of Laser Scanning and CloseRange Photogrammetry - The Last Decade and Beyond. XXth International Society for Photogrammetry and Remote Sensing (ISPRS) Congress, Commission VII, International Society for Photogrammetry and Remote Sensing (ISPRS), Istanbul.

Brandt, T., Semmling, E., Zahl, M., Göring, M., Willemsen, T., 2017: Aufbau und Untersuchung einer Messeinrichtung zur 
Deformationsmessung von bewegten Rotorblättern im Laborversuch mittels optischer 3D-Messtechnik. In: Luhmann/Schumacher (eds.): Photogrammetrie, Laserscanning, Optische 3D-Messtechnik - Beiträge der 16. Oldenburger 3DTage.

Clarke, T.A., Katsimbris. A., 1994. The use of diode laser collimators for targeting 3-D objects. International Archives of Photogrammetry and Remote Sensing. Vol. 30. Part 5. pp. 47-54.

Corten, G. B., 1996: Optical Motion Analysis of Wind Turbines. European Union Wind Energy Conference, Goeteborg, Sweden.

DIN, 2008: Safety of laser products - Part 1: Equipment classification and requirements (IEC 60825-1:2007). German version EN 60825-1:2007.

Edzard, H., 2009: Rotorblatt für Windkraftanlagen, insbesondere für schwimmende Windkraftanlagen, sowie Windkraftanlage mit einem Rotorblatt http://www.patentde.com/20090212/DE102007036917A1.html (24 January 2020)

Eric, V., Göring, M., Luhmann, T., 2017: Intensity of the terrestrial laser scanning data: incident angle and surface reflectance effects. In Luhmann/Schumacher (eds.): Photogrammetrie, Laserscanning, Optische 3D-Messtechnik Beiträge der 16. Oldenburger 3D-Tage, Wichmann Verlag, Offenbach/Berlin, pp. 40-49

García Márquez, F. P., Tobias, A. M., Pinar Pérez, J. M., \& Papaelias, M., 2012: Condition monitoring of wind turbines: Techniques and methods. Renewable Energy, 46, 169-178.

Gikas V., Daskalakis S., 2009: Contribution of Combined RTS and TLS to Dynamic Monitoring of Wind Energy Turbines. 9th Int. Conference on Optical 3-D Measurement Techniques, Vienna, Austria, July 1-3.

GL, 2012. Rules for Classification and Construction - Industrial Services "Guideline for the Certification of Offshore Wind Turbines", Germanischer Lloyd WindEnergie GmbH, Edition 2012, Hamburg, Germany.

Goering, M., Luhmann, T., 2017: Entwicklung eines fächerartigen Distanzmesssystems zur Messung von Rotorblättern - Konzept, Orientierung und erste Ergebnisse. In: Luhmann/Schumacher (eds.): Photogrammetrie, Laserscanning, Optische 3D-Messtechnik - Beiträge der 16. Oldenburger 3DTage.

Grosse-Schwiep, M., Piechel, J., Luhmann, T., 2013: Measurement of Rotor Blade Deformations of Wind Energy Converters with Laser Scanners. ISPRS Annals of the Photogrammetry, Remote Sensing and Spatial Information Sciences II-5/W2, 97-102.

Hau, E. 2008: Windkraftanlagen - Grundlagen, Technik, Einsatz, Wirtschaftlichkeit. Springer

Jepping, C., Luhmann, T., 2016: Deformations from image silhouettes using a kinematic finite element beam model. International Archives of the Photogrammetry, Remote Sensing and Spatial Information Sciences, Volume XL-1/W4, Prague, Czech Republic.

Kim, Y.-K., Kim, Y., Jung, Y. S., Jang, I.G., Kim, K.-S., Kim, S., Kwak, B.M., Kim, E.H., 2012: Developing a robust sensing system for remote relative 6-DOF motion using 1-D laser sensors. IEEE International Systems Conference.

Luhmann, T., Robson, S., Kyle, S., \& Boehm, J., 2020: CloseRange Photogrammetry and 3D Imaging. Berlin, Boston: De Gruyter. doi: https://doi.org/10.1515/9783110607253

Mitka, B., Klapa, P., Gniadek, J., 2019: Use of Terrestrial Laser Scanning for Measurements of Wind Power Stations. Geomatics and environmental Engineering. http://dx.doi.org/10.7494/geom.2019.13.1.39

Özbek, M., 2013: Optical monitoring and operational modal analysis of large wind turbines. $\mathrm{PhD}$ thesis, Delft University of Technology.

Paffenholz, J.-A., Vennegeerts, H., Kutterer H., 2008: High Frequency Terrestrial Laser Scans for Monitoring Kinematic Processes. INGEO 2008 - 4th International Conference on Engineering Surveying. Bratislava, Slovakia, October 23-24

Papadopoulos, K., Morfiadakis, E., Philippidis, T. P., Lekou, D. J., 2000: Assessment of the strain gauge technique for measurement of wind turbine blade loads. Wind Energy, 3/1 3565

PCO, 2020: Datenblatt pco.dimax cs. https://www.pco.de/fileadmin/user_upload/pco-

product_sheets/pco.dimax_cs_data_sheet.pdf. (24 January 2020)

Schmidt Paulsen, U., Erne, O., Schmidt T., 2009: Wind Turbine Operational and Emergency Stop Measurements Using Point Tracking Videogrammetry. In Conference proceedings. Bethel (US): SEM.

Schneemann, J. Rott, A., Doerenkaemper, M., Steinfeld, G., Kuehn, M., 2020: Cluster wakes impact on a far-distant offshore wind farm's power. Wind Energy Science. https://doi.org/10.5194/wes-5-29-2020

Windcomp, 2020: Firma Windcomp GmbH. https://windcomp.jimdo.com/english/. (24 January 2020)

Winstroth, J., Schoen, L., Ernst, B. and Seume, J. R., 2014: Wind turbine rotor blade monitoring using digital image correlation: a comparison to aeroelastic simulations of a multi-megawatt wind turbine. In Journal of Physics: Conference Series (Vol. 524, No. 1, p. 012064). IOP Publishing.

Winstroth, J., Seume, J.R., 2015: Error Assessment of Blade Deformation Measurements on a Multi-Megawatt Wind Turbine based on Digital Image Correlation. Proceedings of the ASME Turbo Expo 2015: Turbine Technical Conference and Exposition. GT2015. June 15-19, 2015, Montréal, Canada

Z+F, 2020: Datenblatt Distanzmesser Z+F Imager 5006. https://www.zf-

laser.com/fileadmin/editor/Datenblaetter/Z_F_IMAGER 5006E X_Datasheet_E.pdf. (24 January 2020) 